\section{Vegetative and Reproductive Growth and Yield of Plukenetia volubilis Plants in Responses to Foliar Application of Plant Growth Regulators}

\author{
C. Yang, D.Y. Jiao, and Z.Q. Cai ${ }^{1}$ \\ Key Laboratory of Tropical Plant Resources and Sustainable Use, \\ Xishuangbanna Tropical Botanical Garden, Chinese Academy of Sciences, \\ Mengla, Yunnan, China \\ H.D. Gong \\ Ecotourism Faculty, Southwest Forestry University, Kunming, China
}

G.Y. Li ${ }^{1}$

Research Institute of Tropical Forestry, Chinese Academy of Forestry, Guangzhou, China

Additional index words. carbohydrate, fruit set, phenological development, photosynthesis, yield components

\begin{abstract}
Plukenetia volubilis Linneo, a tropical recurrent woody oilseed plant native to South America, was successfully introduced in China. A field experiment was conducted to determine the effect of the dry-season foliar sprays once every 2 weeks with $50 \mu \mathrm{M}$ water or five different plant growth regulators (PGRs) viz., gibberellic acid (GA $\mathbf{G}_{3}$ ), kinetin (KIN), indole-3-acetic acid (IAA), abscisic acid (ABA), and salicylic acid (SA) on the growth and yield of $P$. volubilis plants in Xishuangbanna, southwest China. Results showed that PGRs affected the leaf stomatal conductance $\left(g_{S}\right)$ and water-use efficiency $\left(W U E_{i}\right)$, rather than the net photosynthetic rate $\left(P_{N}\right)$. The phenological development of $P$. volubilis plants, including the time of flowering and maturity, and the dynamic pattern of fruit ripening, was not altered by PGR treatments. ABA and SA resulted in highest fruit set, seed oil content, and total fruit or seed oil yield, whereas $\mathrm{GA}_{3}$, IAA, and KIN were effective in increasing seed size. The nonstructural carbohydrates (NSC) are related to subsequent abscission or retention of the developing fruit, which was indicated by the positive relationship between carbohydrate concentration and fruit set across PGR treatments. The positive influences of PGRs on the total fruit yield (increased $4.3 \%$ to $15.2 \%$ ) and total seed oil yield (increased $4.9 \%$ to $24.9 \%$ ) per unit area throughout a growing season were found when compared with the control, depending to a great extent on the balance between vegetative and reproductive growth during the reproductive stage. This study suggests that PGRs, especially for ABA and SA, can become a valuable tool for promoting the seed oil yield of $P$. volubilis plants while maintaining high seed quality in the field.
\end{abstract}

PGR (s) are employed in agriculture and horticulture to obtain specific advantages, such as decreased susceptibility toward biotic and abiotic stress, improved morphological structure, facilitation of harvesting, quantitative and qualitative increases in yield, and modification of plant constituents (Rademacher, 2015; Tantasawat et al., 2015). Most studies on the participation of these compounds in

Received for publication 5 May 2016. Accepted for publication 5 July 2016.

This work was supported financially by grants from the National Science Foundation of China (31370684 and 31170641).

We thank Y.J. Yang, J.X. Zhao, and S.J. Yin for their help with the field work.

C. Yang and D.Y. Jiao contributed equally to this paper.

${ }^{1}$ Corresponding author. E-mail: lgy@ritf.ac.cn; zhiquan.cai@126.com. failed to improve productivity (Day, 2000). The use of PGRs was not recommended for Macadamia, as PGR treatments did not affect the final number of fruits or kernel weights (Trueman, 2010).

Plukenetia volubilis, a perennial woody vine native to South America, is a promising new oilseed crop species belonging to the family Euphorbiaceae. As a fast-growth species, $P$. volubilis plants begin flowering $\approx 5$ months after planting and produce seed with high oil content (Cai, 2011). The seed oil is one of the richest plant sources of unsaturated fatty acids, surpassing the characteristics of the oils used in the worldwide human consumption (Cai et al., 2011). P. volubilis plants grow continuously in tropical regions, and, therefore, flower and fruit almost continuously throughout the year. The fruits are capsules $(\approx 4-7 \mathrm{~cm}$ in diameter) consisting of four to seven pods, with one seed per pod. Although the composition and properties of $P$. volubilis seeds are well known, it is important to increase the fruit or seed yield and oil content for its oil production. In our previous research, the processes of seed oil quantity and quality formation of $P$. volubilis plants are highly variable and depend on environmental conditions and suitable agricultural management practices (Cai, 2011; Cai et al., 2012; Jiao et al., 2012; Yang et al., 2014). One of the potential approaches to improve agronomic productivity is to manipulate the physiology of plants by application of PGRs as observed in some annual and perennial oilseed crops (Abdelgadir et al., 2010; Day, 2000; Ghosh et al., 1991; Prat et al., 2008). However, to date the regulation mechanism of PGRs of $P$. volubilis is still unknown. Therefore, the field experiments were conducted to investigate the effects of PGRs on the plant physiology, growth, and yield of $P$. volubilis plants during a growing season.

\section{Materials and Methods}

Experimental site, plant material, and experimental treatments. Seeds of $P$. volubilis were sown in a nursery in Feb. 2011. When the seedlings were $\approx 20 \mathrm{~cm}$ tall, in Apr. 2011, uniformly sized seedlings were selected and cultivated at open sites at the Xishuangbanna Tropical Botanical Garden of the Chinese Academy of Sciences (lat. $21^{\circ} 56^{\prime} \mathrm{N}$, long. $101^{\circ} 15^{\prime} \mathrm{E}$; $560 \mathrm{~m}$ above sea level) under rainfed condition. The soil was a red brown type and the characteristics of the top $(0-20 \mathrm{~cm})$ layer of soil were $\mathrm{pH} 5.42$, organic carbon $5.65 \%(\mathrm{w} / \mathrm{v})$, total nitrogen $0.34 \mathrm{~g} \cdot \mathrm{kg}^{-1}$, available $\mathrm{N} 46.0 \mathrm{mg} \cdot \mathrm{kg}^{-1}$, available P $14.1 \mathrm{mg} \cdot \mathrm{kg}^{-1}$, and available $\mathrm{K} 22.0$ $\mathrm{mg} \cdot \mathrm{kg}^{-1}$. The climate at Xishuangbanna is dominated by the southwest monsoon with two distinct seasons (a wet season from May to October, and a dry season from November to April). The average annual temperature is $22.9^{\circ} \mathrm{C}$ and the mean annual precipitation is $1500 \mathrm{~mm}$, of which $\approx 85 \%$ occurs in the wet season. The experiment was carried out using 2-year-old $P$. volubilis plants, with $2 \mathrm{~m} \times 2 \mathrm{~m}$ 
spacing. Because $P$. volubilis is a liana species, all plants were supported to a height of $1.6 \mathrm{~m}$ using steel wires.

The field experimental design took the form of randomized complete blocks in $2 \mathrm{~m} \times$ $10 \mathrm{~m}$ sized plots with three replicates for each PGR treatment. Fertilization rates were assigned to the plots and consisted of 150 $\mathrm{kg} \cdot \mathrm{ha}^{-1}$ of a $1: 1: 1(\mathrm{w} / \mathrm{w} / \mathrm{w})$ mix of N-P-K spread in $\approx 1.0$-m-wide zone in June 2012 (Yang et al., 2014). The plants were sprayed once every 2 weeks with $50 \mu \mathrm{M} \mathrm{GA}_{3}$, IAA (Sigma, St. Louis, MO), KIN ( $\mathrm{N}^{6}$-furfuryladenine), SA, ABA, or distilled water (control) at the rate of $200 \mathrm{~mL}$ per plant, respectively, from early Dec. 2012 to late Apr. 2013 (dry season). The foliar foggy spray was done with a hand sprayer that it covered the entire plant to contact leaves and reproductive meristems; spray tips are foggy.

Measurements. In Aug. 2012 and at the end of Mar. 2013, net light-saturated $\mathrm{P}_{\mathrm{N}}$ and $g_{\mathrm{S}}$ were measured under light-saturating irradiance (photosynthetic photon flux density = $1800 \mu \mathrm{mol} \cdot \mathrm{m}^{-1} \cdot \mathrm{s}^{-1}$ ) and ambient $\mathrm{CO}_{2}$ concentration on recently matured, sun canopy leaves, using a portable infrared gas analyzer in open system mode (LI-6400XT; LI-COR, Lincoln, NE). Intrinsic $\mathrm{WUE}_{\mathrm{i}}$ was calculated as the ratio of $\mathrm{P}_{\mathrm{N}}$ to $g_{\mathrm{S}}$. Stem samples in each treatment were collected and were dried at $70{ }^{\circ} \mathrm{C}$ and ground to a powder fine enough to pass a 40-mesh screen. The dried stem tissue was analyzed for NSC, defined as the sum of starch and soluble sugar (glucose, fructose, and sucrose), following the enzymatic digest and ultraviolet spectrophotometry methods modified from DuBois et al. (1956). The latest fully expanded leaves were detached and weighted immediately to record fresh weight. Then the leaves were floated in distilled water until they reached a constant weight. Thereafter, leaf samples were dried until constant weight at $70{ }^{\circ} \mathrm{C}$ in an oven. The leaf relative water content (LRWC) was determined as: LRWC $(\%)=[$ fresh weight - dry weight (DW)]/(fully turgid weight-DW). Specific leaf area (SLA; i.e., area of the leaf in $\left.\mathrm{cm}^{2} \cdot \mathrm{g}^{-1} \mathrm{DW}\right)$ was also calculated. At the end of Apr. 2013, stem diameter at $5 \mathrm{~cm}$ above the soil was also measured with a calliper to assess the plant growth.

Mature fruit from all $P$. volubilis plants in each plot were harvested seven times, by hand, in each replicate subplot, throughout the period of fruit ripening. The total DW of fruit per plot was measured at each harvest. Also at each harvest, subsamples of mature fruit were peeled and the DW (size) of all seeds per plot was recorded. Seed oil contents were determined by the minispec mq-one Seed Analyzer (Bruker Optik GmbH, Germany); then the total seed oil yield $\left(\mathrm{ha}^{-1}\right)$ throughout the growing season was then calculated by adding the values from each harvest. A total of 40 female flowers with their stigmata open were randomly tagged each plot in late Dec. 2012 and Feb. 2013, respectively; and formation of fruits was determined within 3 weeks. The percentage fruit set was calculated as the number of set fruits divided by the number of female flowers $\times 100$.

Statistical analysis. All data are presented as mean values \pm SD. The leaf and growth traits and fruit set percentage between the different PGR treatments were analyzed by one-way analysis of variances (ANOVAs) test (Tukey's test). We used two-way ANOVA to compare seed traits and fruit yield between PGR treatments, different sampling times and their interactions. We then used least significant difference contrasts to examine whether each trait differed between PGR treatments within and between the different sampling times. Data were tested for normality and homogeneity of variance and, when necessary, were $\log _{10}$-transformed before analysis. All statistical analyses were conducted using SPSS version 13.0 (SPSS, Chicago, IL).

\section{Result and Discussion}

Morphological, physiological, and growth traits. Natural drought is a slow-onset and prolonged phenomenon caused by a rainfall deficit combined with other predisposing factors. Ranging from $88.6 \%$ to $91.2 \%$, LRWCs marginally differed between the different PGR treatments $(P=0.068)$ at the end of the dry season (Fig. 1A). The relatively high LRWC
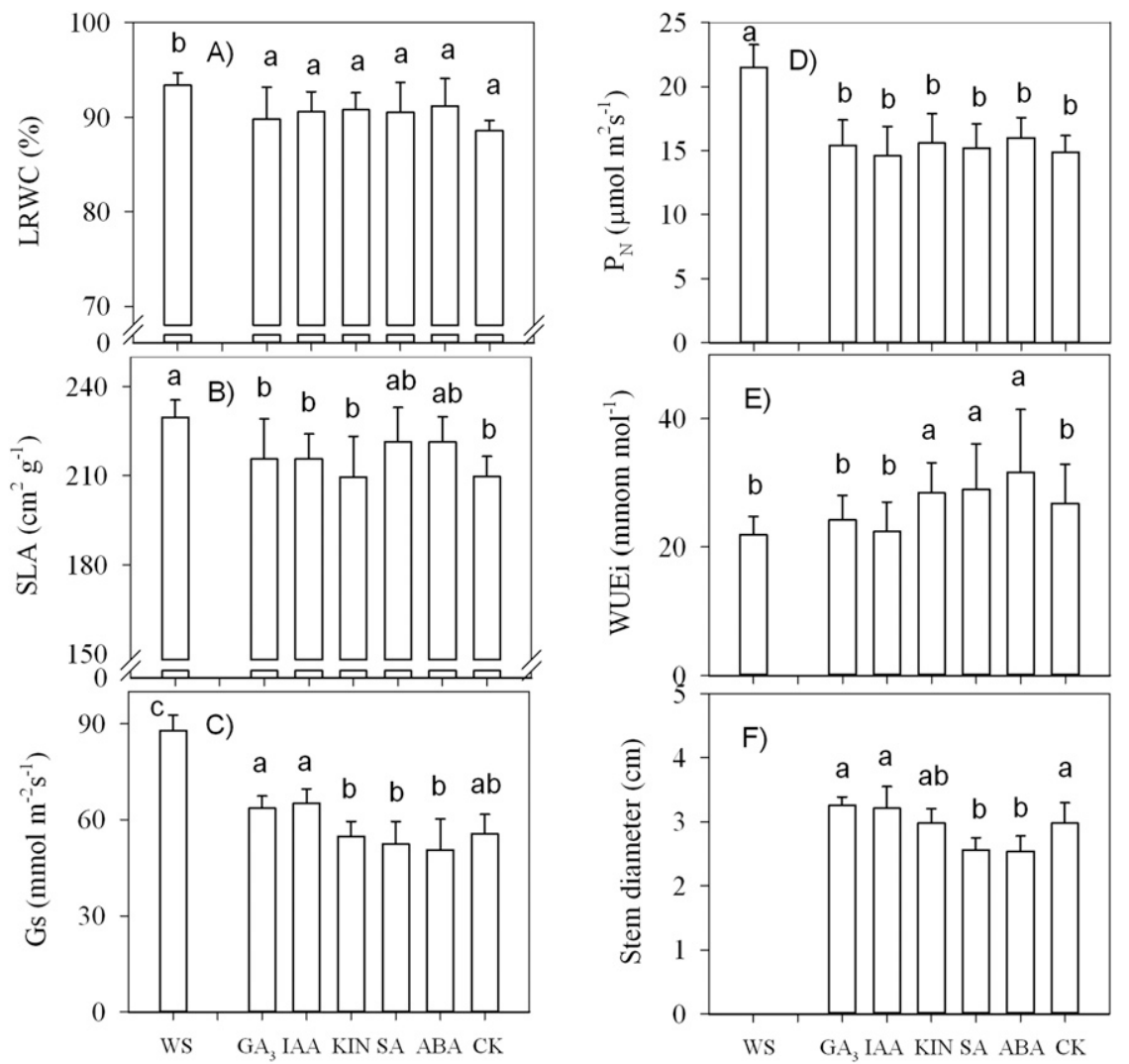

Fig. 1. Leaf and plant growth traits (means $\pm \mathrm{SD}, \mathrm{n}=3-5$ ) of Plukenetia volubilis plants in the wet season (WS) and treated with different plant growth regulators in the dry season. Different letters indicate significant differences at $P<0.05 . \mathrm{ABA}=$ abscisic acid; $\mathrm{CK}=$ control (water); $\mathrm{GA}_{3}=$ gibberellic acid; Gs = gas stomatal conductance; IAA = indole-3-acetic acid; KIN = kinetin; $\mathrm{LRWC}=$ leaf relative water content; $\mathrm{P}_{\mathrm{N}}=$ the light-saturated photosynthetic rate; $\mathrm{SA}=$ salicylic acid; $\mathrm{SLA}=$ specific leaf area; WUEi $=$ intrinsic water-use efficiency. indicate that the leaves of water-stressed $P$. volubilis plants required only a small amount of water to reach water saturation, allowing the plants to withstand arid environments. In general, leaves that develop under drought conditions have lower SLA values than those that develop under optimum water conditions not change significantly when plants were subjected to 4 months of water deficit in the dry season and did not differ between different PGR treatments (Fig. 1B). SLA represents the area through which water must diffuse to leave. Therefore, a stable SLA is important to maintain leaf function and to conserve water under drought conditions (Jiao et al., 2012). The main mechanisms responsible for drought resistance in plants are improved water uptake and/or reduced water loss; the latter being regulated by gaseous exchange through the open of stomata on their leaves. Leaf $g_{S}$ significantly differed between the different PGR treatments, with the low values found in $\mathrm{KIN}, \mathrm{ABA}$, and SA treatments and high values found in $\mathrm{GA}_{3}$ and IAA treatments (Fig. 1C). The opening and closing of stomata is regulated by the integration of environmental signals and endogenous hormonal stimuli. Among phytohormones, ABA is the bestknown stress hormone that closes the stomata and regulates water status, although jasmonic acid, brassinosteroids, cytokinins, IAA, or (Chaves et al., 2003). In our study, SLA did 


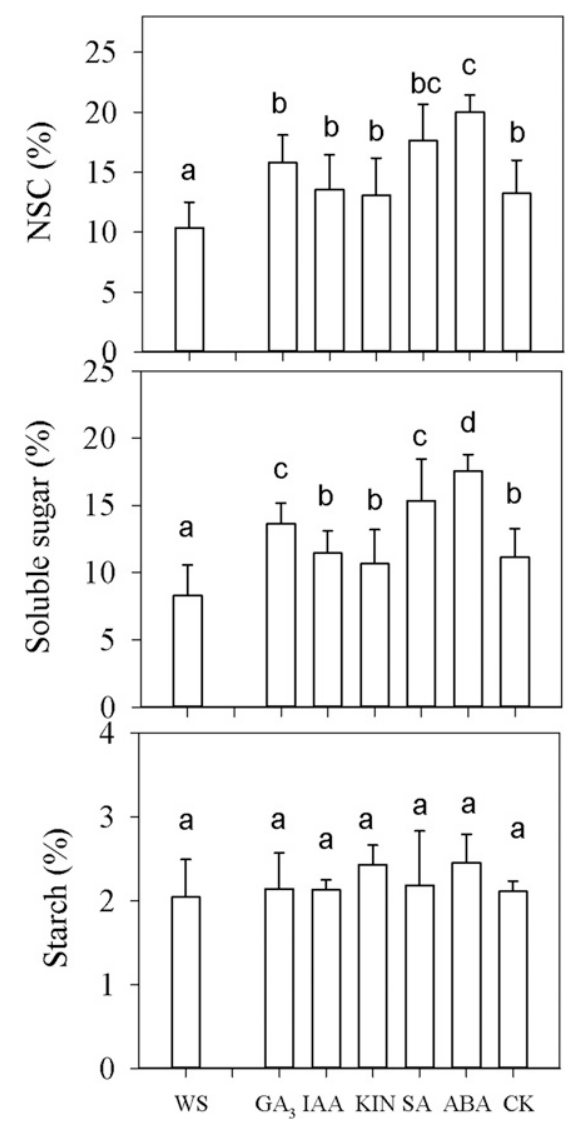

Fig. 2. Nonstructural carbohydrate (NSC) concentration in stem of Plukenetia volubilis plants in the wet season (WS) and treated with different plant growth regulators in the dry season. Mean values with a different letter indicate significant differences at $P<0.05$.

ethylene are also involved in the stomatal response to stresses (Davies and Zhang, 1991). Generally, ABA and SA are positive regulators of stomatal closure; cytokinins and IAA in low physiological concentrations promote stomatal opening, whereas they are able to inhibit this process in high concentrations (Rademacher, 2015).

Compared with the wet season when environmental conditions (water, temperature, and light) were close to optimal and the leaves were in peak physiological condition (Cai et al., 2007), the net light-saturated $\mathrm{P}_{\mathrm{N}}$ in $P$. volubilis plants during the dry season was much lower, and the effect of PGRs on $\mathrm{P}_{\mathrm{N}}$ was minor (Fig. 1D). The effects of exogenous $\mathrm{ABA}$ on $\mathrm{P}_{\mathrm{N}}$ in response to drought have produced various results, ranging from increases (Rajasekaran and Blake, 1999) to decreases (Li et al., 2004). Such variation in results can be explained by the fact that the ABA effects on stress tolerance may depend on the extent and duration of the dehydration as well as on the sensitivity of the particular species to drought. The intrinsic WUEi was improved by KIN, ABA, and SA treatments, owing to the decreased $g_{\mathrm{s}}$ (Fig. 1E). It was also found that exogenous application of $\mathrm{SA}$ enhanced the crop growth and $\mathrm{WUE}_{\mathrm{i}}$ in sunflower under both limited and wellwatered conditions (Hussain et al., 2008).

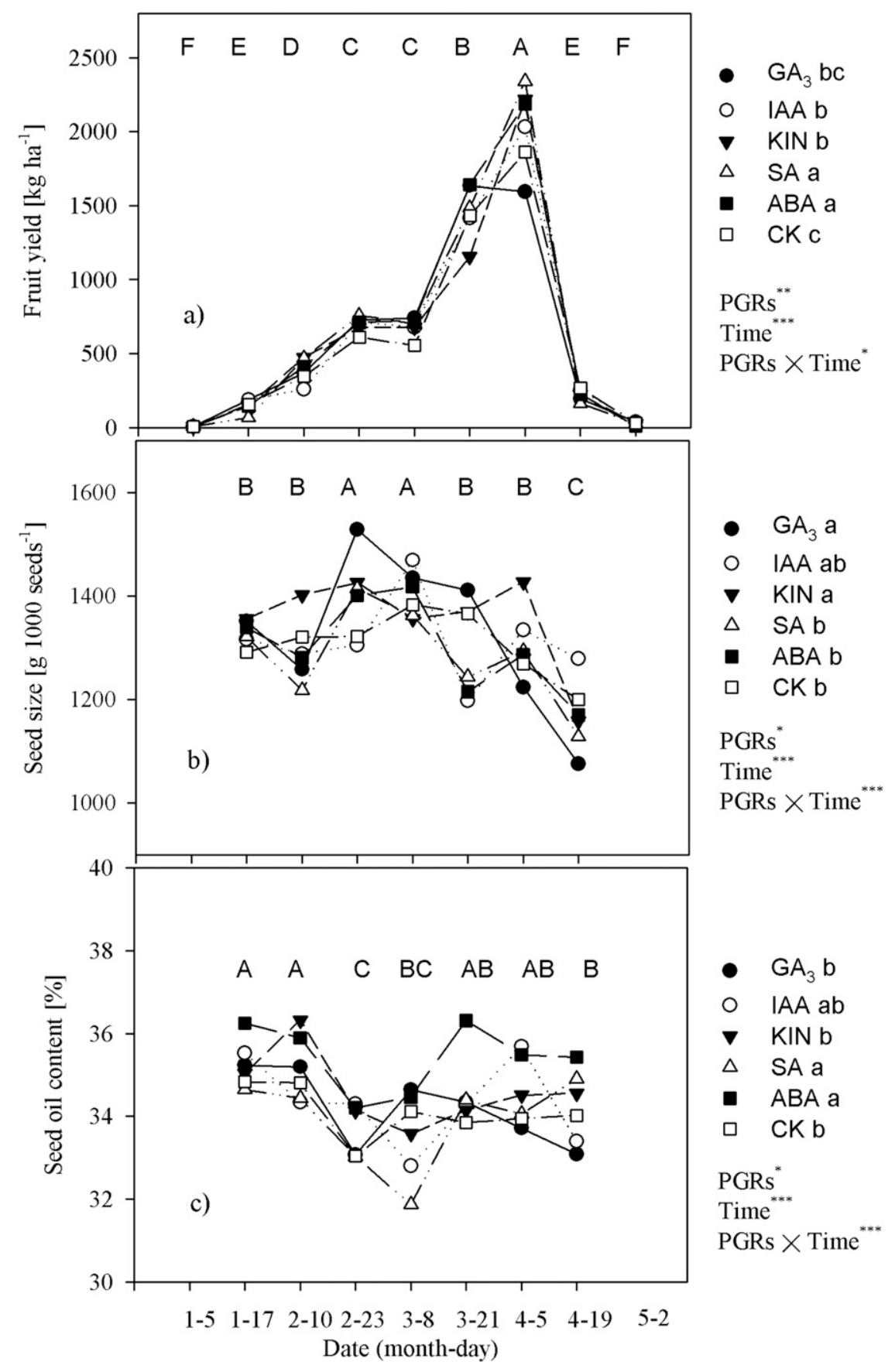

Fig. 3. Time dynamics of the mature fruit yield per unit area, seed size, and seed oil content of Plukenetia volubilis plants treated with different plant growth regulators (PGRs) in a growing season. Mean values with different small and capital letters for each trait indicate significant differences among PGRs and among sampling date at $P<0.05$, respectively. *, **, ***Significant at $P<0.05,0.01$, or 0.001 , respectively.

PGRs we used affected plant growth (stem diameter) with the lowest values found in ABA and SA treatments (Fig. 1F), attributing to the influence in leaf areas, rather than leaf $\mathrm{P}_{\mathrm{N}}$. The effect of exogenous ABA induced in the decrease in plant biomass mainly by inhibiting leaf expansion (Agehara and Leskovar, 2014; Li et al., 2004). In addition, the ABA-induced reduction in total leaf transpiration will prevent dehydration of leaf tissues (i.e., high LWRC) and enhance the chance for survival under prolonged drought stress (Chaves et al.,
2003). This is especially important for the large-scale cultivation of $P$. volubilis plants in the dry-land agricultural farm because some plants died due to natural drought (Z.Q. Cai, personal observation), although ABA application can improve the drought resistance of $P$. volubilis seedlings by inducing the antioxidant enzymes activities ( $\mathrm{Su}$ et al., 2015).

Plants produce, store, invest, and lose carbon compounds. On a whole-plant basis, the mobile NSC (largely starch and sugars) indicate a plant's actual carbon supply status 

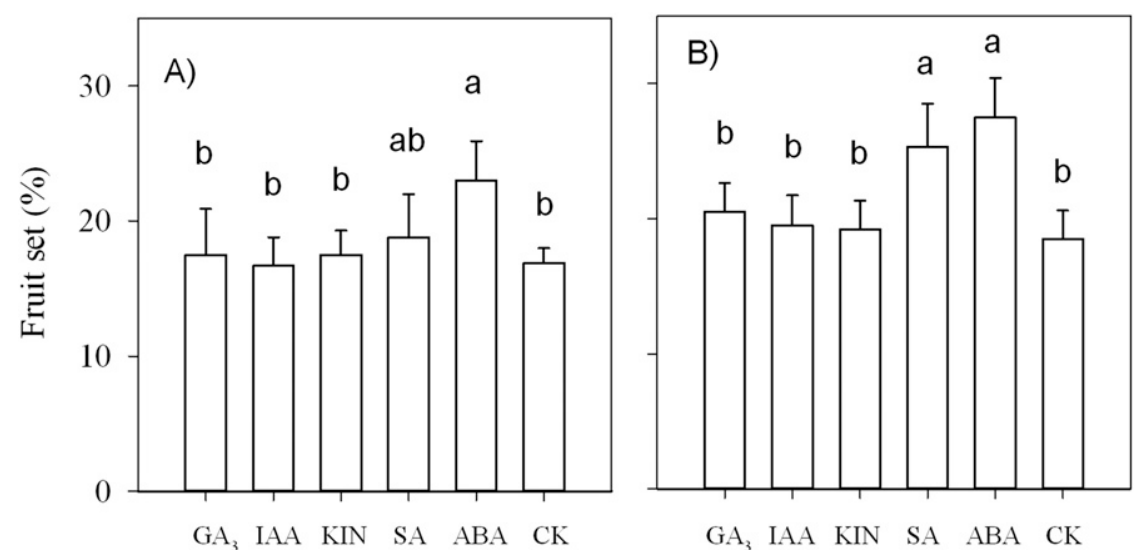

Fig. 4. Fruit set percentage of Plukenetia volubilis plants labeled in late (A) Dec. 2012 and (B) Feb. 2013 , respectively, under different plant growth regulator (PGR) treatments. Mean values with a different letter indicate significant differences between PGR treatments at $P<0.05$.
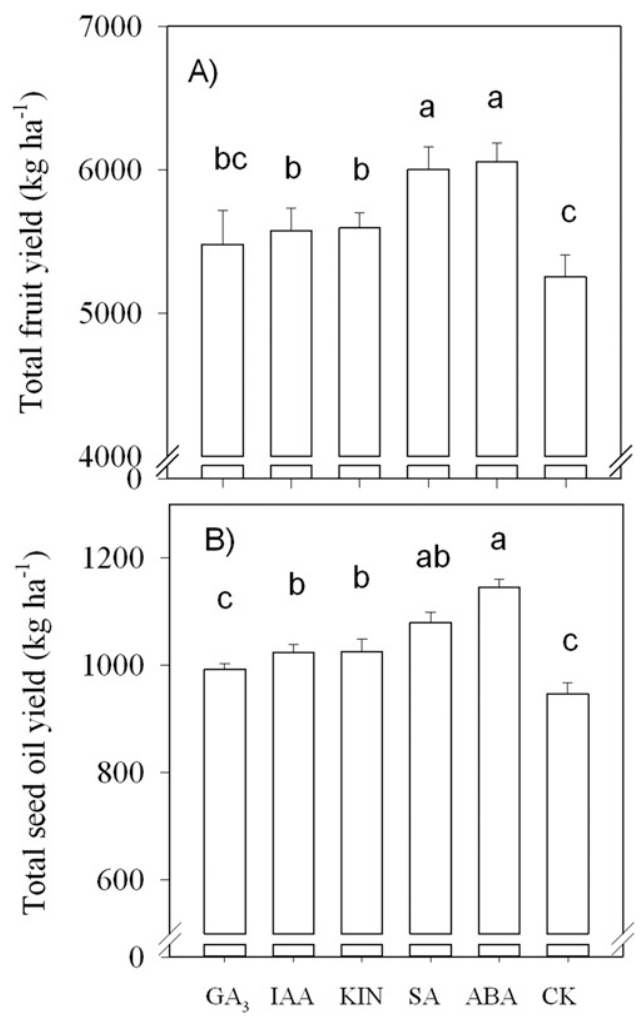

Fig. 5. Total fruit yield and total seed oil yield in Plukenetia volubilis plants treated with different plant growth regulators throughout a growing season. Mean values with a different letter indicate significant differences at $P<0.05$.

and reflect its capital for flushing and reproduction and its buffering capacity with respect to replacement of lost tissue. Compared with the wet season, the stem NSC concentration in $P$. volubilis plants in the dry season was much higher. PGR treatments significantly affected the stem soluble sugar and NSC concentration with the highest values found in $\mathrm{ABA}$ treatment, but had less effect on starch concentration at the end of the dry season (Fig. 2). The negative trend between NSC concentration and stem extension provided evidence that growth decline in $P$. volubilis plants was dependent on some factor, such as reductions in turgor-driven cell expansion or constraints on phloem transport, rather than local NSC storage. On the other hand, this result supported the hypothesis that NSC may be an active carbon sink of $P$. volubilis plants, crucial to maintaining hydraulic function in the dry season, although a complete, whole-plant representation of organ samples across seasons is crucial. Indeed, this hypothesis would explain why NSC pools were maintained before tree growth, especially under drought conditions (Bustan et al., 2011; Chapin et al., 1990).

Plant reproductive traits. PGRs may play important roles in controlling crop reproductive development under drought conditions (Liu et al., 2004). Floral initiation is affected by the cycle of flush development, and time to flowering and harvesting of perennial woody plant (e.g., Coffea arabica) and some annual plants can be manipulated by exogenous applications of PGRs, $\mathrm{GA}_{3}$ in particular (Matsumoto, 2006; Schuch and Fuchigami, 1992; Wilkie et al., 2008), although treatment effects were dependent on the time of growth regulator application. However, PGRs did not affect the phenological development of $P$. volubilis plants, including the initial time of flowering and maturity, and the dynamic pattern of fruit ripening (Fig. 3a). Fruits start to ripe to a dark brown color in early January, and the fruit ripening peak period occurred in March and April (cf. Yang et al., 2014).

The exogenous ABA- and SA-induced decreases in plant growth around the critical seed-filling period also resulted in the lowest fruit abortion among the different PGR treatments during both early and middle of the dry season (Fig. 4a and b). Carbohydrate availability could influence yield by adjusting fruit number to the metabolite supply of the tree through the premature abscission of flowers and developing fruits. There is a positive relationship between NSC concentrations and fruit set of $P$. volubilis plants across the different PGR treatments $(r=0.67, P=$ 0.044 ), which also found in grapevine (Lebon et al., 2008) and Avocado (Alcaraz et al., 2013). This is in line with the fact that the NSC reserves, especially for soluble sugar, accumulated at anthesis, are related to subsequent abscission or retention of the developing fruit (Chapin et al., 1990). However, the status of carbohydrates is not a yield determinant of cacao (Groeneveld et al., 2010) and intensively cultivated olive trees (Bustan et al., 2011), although it may play a significant role in their survival strategy.

Yield and yield components. It is well documented that the fruit or seed numbers and size were decisive factors for seed yield of oilseed crops (Jiao et al., 2012; Ozer, 2003). There was significant PGRs $\times$ sampling date interaction for the fruit yield, seed size (mass per 1000 seeds) and seed oil content, implying that the responsiveness to PGRs differed among the sampling time (Fig. 3A-C). The seeds matured in the middle of the dry season had relatively large seed size but had low oil content. It is likely that increased abiotic stress during the seedfilling period resulted in seeds with a reduced oil content (Rotundo and Wesgate, 2009). Contrary to our previous research that seed size and seed oil content had a relatively high and constant heritability in $P$. volubilis plants in response to agricultural management practices, such as water, fertilization, and planting density (Jiao et al., 2012; Yang et al., 2014), PGRs significantly affected seed size (i.e., weight) and seed oil content, with the large seed size being observed in $\mathrm{GA}_{3}, \mathrm{KIN}$, and IAA treatments, whereas high seed oil content was found in ABA and SA treatments across different sampling date. Because of an essential role in seed development (Singh 


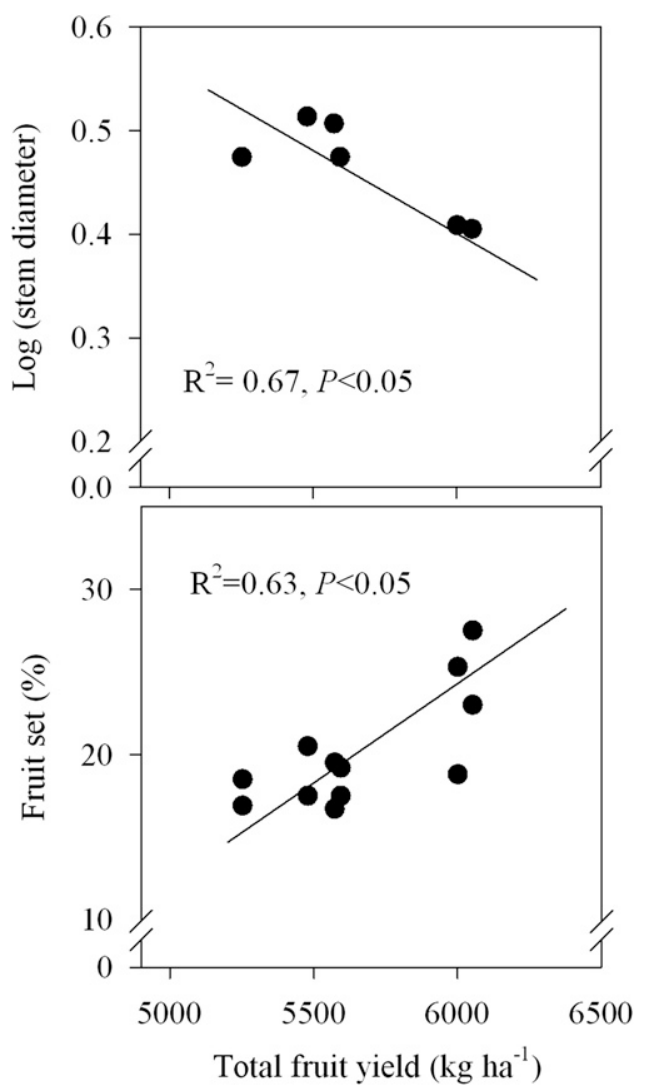

Fig. 6. Relationships between total fruit yield and stem diameter and fruit set percentage in Plukenetia volubilis plants across different plant growth regulator treatments.

et al., 2002), $\mathrm{GA}_{3}$ is registered for use to increase fruit or seed size of numerous vine and fruit crops: grape (Vitis vinifera), citrus (Citrus spp.), banana (Musa spp.), currant (Ribes aureum), and pineapple (Ananas comosus) (Valent BioSciences Corp, 2015).

All the PGRs we used increased the total fruit yield (by $4.3 \%$ to $15.2 \%$ ) and total seed oil yield (by $4.9 \%$ to $24.9 \%$ ) of $P$. volubilis plants throughout a growing season as compared with control, with maximum increase being observed in $\mathrm{ABA}$ and SA treatments followed by KIN, IAA, and $\mathrm{GA}_{3}$, respectively (Fig. 5a and b). This was consistent with the positive influence of PGRs on the productivity of several oilseed crops (Abdelgadir et al., 2010; Ghosh et al., 1991). Exogenous application of ABA and SA has been found very effective in reducing the deleterious effect of activated oxygen species, especially in drought (Alscher et al., 1997; Hussain et al., 2008). As P. volubilis plants mainly matured in the dry season, induction of drought tolerance in $P$. volubilis plants by exogenous $\mathrm{ABA}$ and $\mathrm{SA}$ and its derivatives might have a significant practical role in its production. The fruit yield was relatively low in $\mathrm{GA}_{3}, \mathrm{KIN}$, and IAA treatments although they had relatively large seed size. Therefore, the increased fruit numbers per unit area, rather than fruit or seed size, was largely responsible for the influences of PGRs on the total fruit yield of $P$. volubilis plants, which was consistent with the result of our previous studies (Jiao et al., 2012; Yang et al., 2014). On the other hand, Ozer (2003) suggested that seed size is another primary factor that determined the seed yield of winter oilseed rape (Brassica napus).

As a wind-dispersed species with welldeveloped reproductive organs (i.e., flower and fruit numbers; Jiao et al., 2012), seed production in $P$. volubilis plants depends mainly on the availability of current photoassimilate and storage resources (i.e., carbohydrates) to make seeds. Vegetative growth is highly responsible for the number and size of the reproductive sink (i.e., number of flowers and capsules) during the reproductive stage (Cai 2011; Cai et al., 2012). Although the fruit yield was positively related to the fruit set as expected, the increased fruit yield was negatively accompanied by an increased plant biomass across PGR treatments (Fig. 6), contrasting with our previous results of $P$. volubilis plants in response to light intensity, water, fertilization, and planting density (Cai, 2011; Jiao et al., 2012; Yang et al., 2014). PGRs are known to enhance the source-sink relationship and stimulate the translocation of photoassimilates thereby helping in effective flower formation, fruit, and seed development, and ultimately enhance productivity of the crops (Agehara and Leskovar, 2014; Rademacher, 2015). This, when coupled with the ABA- and SA-induced mobilization of metabolites to the developing fruits during the drought conditions when current available photoassimilates was strongly limited, may have stimulated the switch from vegetative to reproductive growth and, hence, caused an increase in fruit yield, as observed herein. There was also reported that PGRs increased the yield and harvest index, but did not affect aboveground biomass of alfalfa plants (Zhang et al., 2009).

\section{Conclusion}

For the first time, this study suggests that PGRs can become a valuable tool for promoting the seed oil yield of $P$. volubilis plants with ABA and SA having the largest effects, especially under drought conditions in the field. The yield and development of $P$. volubilis plants depended to a great extent on the balance between vegetative to reproductive growth during the reproductive stage in the dry season. Additional studies should be conducted to determine whether or not the effect of PGRs at different concentrations on the seed or oil yield was consistent over the years.

\section{Literature Cited}

Abdelgadir, H.A., A.K. Jäger, S.D. Johnson, and J. van Staden. 2010. Influence of plant growth regulators on flowering, fruiting, seed oil content, and oil quality of Jatropha curcas. S. Afr. J. Bot. 76:440-446.

Agehara, S. and D.I. Leskovar. 2014. Growth reductions by exogenous abscisic acid limit the benefit of height control in diploid and triploid watermelon transplants. HortScience 49:465-471

Alcaraz, M.L., J.I. Hormaza, and J. Rodrigo. 2013. Pistil starch reserves at anthesis correlate with final flower fate in avocado (Persea americana). PLoS One 22:e78467.

Aljuburi, H.J., H. Al-Masry, and S.A. Al-Muhanna. 2000. Fruit characteristics and productivity of date palm trees (Phoenix dactylifera L.) as affected by some growth regulators. HortScience 35:476-477.

Alscher, R.G., J.L. Donahne, and C.L. Cromer. 1997. Reactive oxygen species and antioxidants: Relationships in green cells. Physiol. Plant. 100:224-233.

Bustan, A., A. Avni, S. Lavee, I. Zipori, Y. Yeselson, A.A. Schaffer, J. Riovo, and A. Dag. 2011. Role of carbohydrate reserves in yield production of intensively cultivated oil olive (Olea europaea L.) trees. Tree Physiol. 31:519-530.

Cai, Z.Q. 2011. Shade delayed flowering and decreased photosynthesis, growth and yield of Sacha Inchi (Plukenetia volubilis) plants. Ind. Crops Prod. 34:1235-1237.

Cai, Z.Q., Y.J. Chen, and F. Bongers. 2007. Seasonal changes in photosynthesis and growth of Zizyphus attopensis seedlings in three contrasting microhabitats in the tropical seasonal rain forest. Tree Physiol. 27:827-836.

Cai, Z.Q., D.Y. Jiao, X.S. Tang, X.S. Dao, and C.T. Cai. 2012. Leaf photosynthesis, growth and seed chemicals of Sacha Inchi (Plukenetia volubilis) plants cultivated along an altitude gradient. Crop Sci. 52:1859-1867.

Cai, Z.Q., Q. Yang, S.X. Tang, and X.S. Dao. 2011 Nutritional evaluation in seeds of a woody oil crop, Plukenetia volubilis Linneo. Acta Nutr. Sin. 33:193-195.

Chaves, M.M., J.P. Maroco, and J.S. Pereira. 2003. Understanding plant responses to drought from genes to the whole plant. Func. Plant Biol. 30:239-264. 
Chapin, F.S., E.D. Schulze, and H.A. Mooney. 1990. The ecology and economics of storage in plants. Annu. Rev. Ecol. Syst. 21:423-447.

Davies, W.J. and J.H. Zhang. 1991. Root signals and the regulation of growth and development of plants in drying soil. Annu. Rev. Plant Physiol. Plant Mol. Biol. 42:55-76.

Day, J. 2000. The effect of plant growth regulator treatments on plant productivity and capsule dehiscence in sesame. Field Crops Res. 66: 15-24.

DuBois, M., K.A. Gilles, J.K. Hamilton, P.A. Rebers, and F. Smith. 1956. Colorimetric method for determination of sugars and related substances. Anal. Chem. 28:350-356.

Ghosh, R.K., B.K. Mandal, and B.N. Chatterjee. 1991. Effect of growth regulators on the productivity of some major oilseed crops. J. Agron. Crop Sci. 167:221-228.

Groeneveld, J.H., T. Tschamtke, G. Moser, and Y. Clough. 2010. Experimental evidence for stronger cacao yield limitation by pollination than by plant resources. Perspect. Plant Ecol. Evol. Syst. 12:183-191.

Hussain, M., M.A. Mali, M. Farooq, M.Y. Ashraf, and M.A. Cheema. 2008. Improving drought tolerance by exogenous application of glycinebetaine and salicylic acid in sunflower. J. Agron. 194:193-199.

Jiao, D.Y., M.H. Xiang, W.G. Li, and Z.Q. Cai. 2012. Dry-season irrigation and fertilisation affect the growth, reproduction, and seed traits of Plukenetia volubilis L. plants in a tropical region. J. Hort. Sci. Biotechnol. 87:311-316.

Lebon, G., G. Wojnarowiez, B. Holzapfel, F. Fontaine, N. Vaillant-Gaveau, and C. Clcbment. 2008. Sugars and flowering in the grapevine
(Vitis vinifera L.). J. Expt. Bot. 59:25652578.

Li, C., C. Yin, and S. Liu. 2004. Different responses of two contrasting Populus davidiana populations to exogenous abscisic acid application. Environ. Exp. Bot. 51:237-246.

Liu, F., C.R. Jensen, and M.N. Andersen. 2004. Pod set related to photosynthetic rate and endogenous ABA concentration in soybeans subjected to different water regimes and exogenous $\mathrm{ABA}$ and $\mathrm{BA}$ at early reproductive stages. Ann. Bot. (Lond.) 94:405-411.

Matsumoto, T.K. 2006. Gibberellic acid and benzyladenine promote early flowering and vegetative growth of Miltoniopsis orchid hybrids. HortScience 41:131-135.

Ozer, H. 2003. Sowing date and nitrogen rate effects on growth, yield and yield components of two summer rapeseed cultivars. Eur. J. Agron. 19:453-463.

Prat, L., C. Botti, and T. Fichet. 2008. Effect of plant growth regulators on floral differentiation and seed production in Jojoba (Simmondsia chinensis (Link) Schneider). Ind. Crops Prod. 27:44-49.

Rademacher, W. 2015. Plant growth regulators: Backgrounds and uses in plant production. J. Plant Growth Regulat. 34:845-872.

Rajasekaran, L.R. and T.J. Blake. 1999. New plant growth regulators protect photosynthesis and enhance growth under drought of Jack pine seedlings. J. Plant Growth Regulat. 18: $175-181$.

Rotundo, J.B. and M.E. Wesgate. 2009. Metaanalysis of environmental effects on soybean seed composition. Field Crops Res. 110: 147-156.
Schuch, U.K. and L.H. Fuchigami. 1992. Growth regulators and pruning affect flower and fruit development in Coffea arabica $\mathrm{L}$. HortScience 27:691.

Singh, D.P., A.M. Jermakow, and S.M. Swain. 2002. Gibberellins are required for seed development and pollen tube growth in Arabidopsis. Plant Cell 14:3133-3147.

Su, Z., Y. Luo, T. Bi, Y. Luo, Y. Zhao, and Q. Lan. 2015. Spraying of abscisic acid on the leaf improved drought resistance of Plukentia volubilis seedling. Yunnan Nong Ye Da Xue Xue Bao 30:239-244.

Tantasawat, P.A., A. Sorntip, and P. Pornbungkerd. 2015. Effects of exogenous application of plant growth regulators on growth, yield, and in vitro gynogenesis in cucumber. HortScience 50:374-382.

Trueman, S.J. 2010. Benzyladenine delays immature fruit abscission but does not affect final fruit set or kernel size of Macadamia. Afr. J. Agr. Res. 5:1523-1530.

Valent BioSciences Corp. 2015. ProGibb ${ }^{\circledR}$ Plant Growth Regulator. <https://www.valent.com/ agriculture/products/progibb/\#fragment-1>.

Wilkie, J.D., M. Sedgle, and T. Olesen. 2008. Regulation of floral initiation in horticultural trees. J. Expt. Bot. 59:3215-3228.

Yang, C., D.Y. Jiao, Y.J. Geng, C.T. Cai, and Z.Q. Cai. 2014. Planting density and fertilisation affect the seed and oil yields in Plukenetia volubilis L. plants independently. J. Hort. Sci. Biotechnol. 89:201-207.

Zhang, T., X. Wang, Y. Wang, and P. Mao. 2009. Plant growth regulator effects on balancing vegetative and reproductive phases in Alfalfa seed yield. Agron. J. 101:1139-1145. 